\title{
Spin-Labelled 1-Ethyl-1-Nitrosourea Prevents Doxorubicin and Bleomycin- Induced Oxidative Stress in Lungs, Hearts and Kidneys of Tumour-Bearing Mice
}

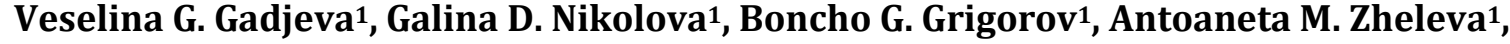 \\ Anna N. Tolekova' ${ }^{2}$, Maya I. Vasileva ${ }^{3}$ \\ ${ }^{1}$ Department of Chemistry and Biochemistry, Faculty of Medicine, Trakia University, Stara Zagora, Bulgaria \\ ${ }^{2}$ Department of Physiology, Pathophysiology and Pharmacology, Faculty of Medicine, Trakia University, Stara \\ Zagora, Bulgaria \\ ${ }^{3}$ Laboratory of Oncopharmacology, National Cancer Institute, Sofia, Bulgaria \\ Email: vgadjeva@mf.uni-sz.bg
}

Received $* * * * 2014$

Copyright (C) 2014 by authors and Scientific Research Publishing Inc.

This work is licensed under the Creative Commons Attribution International License (CC BY). http://creativecommons.org/licenses/by/4.0/

\section{Open Access}

\section{Abstract}

This study was carried out to determine the possible protective effect of 1 -ethyl-3-[4- $(2,2,6$, 6-tetramethylpiperidine-1-oxyl)]-1-nitrosourea (SLENU), recently synthesised in our laboratory on doxorubicin and bleomycin-induced oxidative toxicity in C57 black tumour-bearing mice. Specifically, alterations in some biomarkers of oxidative stress, such as lipid peroxidation products measured as malondialdehyde (MDA) levels and activities of the antioxidant enzymes, superoxide dismutase (SOD) and catalase (CAT), were studied in lung, heart and kidney homogenates isolated from C57 black tumor-bearing mice after i.p. treatment with solutions of DOX (60 mg/ $\mathrm{kg})$ and BLM $(60 \mathrm{mg} / \mathrm{kg})$. The same biomarkers were also measured after i.p. pretreatment of mice with SLENU $(100 \mathrm{mg} / \mathrm{kg})$. After treatment with doxorubicin, heart and kidney homogenates of mice had significantly higher productions of lipid peroxidation compared to lung homogenates. It was accompanied by increased activity of the antioxidant defence enzyme superoxide dismutase and decreased activity of catalase. Bleomycin-induced oxidative stress was confirmed by significantly higher production of lipid peroxidation in lungs compared to heart homogenates, elevation of the antioxidant activity of superoxide dismutase and decreased activity of catalase enzymes. After pretreatment of the mice with SLENU, the levels of all studied oxidative stress biomarkers were significantly improved in comparison with those of the mice treated alone with either bleomycin, or doxorubicin. The present results and those from a previously demonstrated superoxide scavenging activities (SSA) of the nitrosourea SLENU have enabled us to explain the protective effect of the spin-labelled nitrosourea on doxorubicin and bleomycin-induced oxidative stress by scaveng- 
ing of $\cdot \mathrm{O}_{2}^{-}$and increased $\cdot \mathrm{NO}$ release.

Keywords

Doxorubicin, Bleomycin, Spin-Labelled, Superoxide Dismutase, Catalase, Lipid Peroxidation

\section{Introduction}

Among the anticancer drugs, doxorubicin (DOX) and bleomycin (BLM) are the most effective anti-neoplastic drugs in current clinical practice. Doxorubicin, (daunorubicin, epirubicin, and andidarubicin) possess a potent and broad-spectrum antitumor activity against a variety of human solid tumors and hematological malignancies. However, the clinical usefulness of DOX is restricted, since it has several acute and chronic side effects, particularly a dose-dependent myocardial injury, which can lead to a potentially congestive heart failure [1]. The production of free radicals and oxidative stress is closely involved with DOX action, regarding both anti-tumour and toxic effects. DOX is transformed into a semiquinone free radical that reacts with molecular oxygen to produce thesuperoxide radical $\left(\mathrm{O}_{2}^{-}\right)$and it converts DOX into quinone. This quinone-semiquinone cycle generates large amounts of $\mathrm{O}_{2}^{-}$, which subsequently give rise to ROS and RNS species such as hydrogen peroxide $\left(\mathrm{H}_{2} \mathrm{O}_{2}\right)$, hydroxyl radical $\left(\mathrm{HO}^{-}\right)$or peroxynitrite $\left(\mathrm{ONOO}^{-}\right)$[2] [3].

Bleomycin has been shown to be an effective antitumor agent in the treatment of testicular carcinoma and lymphoma. It has also been used as cytotoxic therapies for patients with other germ cell tumors, Kaposi's sarcoma, and head and neck carcinoma. A serious complication of bleomycin therapy is pulmonary fibrosis, which may occur in up to $10 \%$ of patients to a variable degree [4] [5]. Bleomycin can bind metal ions and DNA at the same time at two different sites, and this complex can generate ROS such as superoxide and hydroxyl radicals [6] [7]. Studies with antioxidants such as $\mathrm{N}$-acetylcysteine or bilirubin showed effective protection of rats against bleomycin-induced lung fibrosis [8].

Reduced toxicity and increased antineoplastic properties were achieved when nitroxyl (aminoxyl) groups, such as 2,2,6,6-tetramethylpiperidine-1-oxyl (TMPO), were introduced in chemical structure of certain antitumour drugs [9] [10]. Following this finding, we have synthesised a number of spin-labelled analogues of the anticancer drug 1-(2-chloroethyl)-3-cyclohexyl-1-nitrosourea (CCNU). Some of these compounds showed advantages over CCNU, by having lower toxicity and higher anticancer activity against some experimental tumour models [11]-[14]. Using the EPR method we had shown that spin-labelled nitrosoureas could scavenge $\cdot \mathrm{O}_{2}^{-}$ and thus exhibited high superoxide scavenging activity (SSA) [15]. Moreover, by our studies, we have demonstrated beneficial effects of SLENU, recently synthesized in our laboratory, on drug-induced oxidative toxicity in rat blood and in liver of mice [16]-[18].

Therefore, the aim of the present study was to investigate whether, pretreatment with spin-labeled nitrosourea SLENU (Figure 1) possessing high SSA would decrease oxidative toxicity in hearts induced by application of antitumor drug DOX and oxidative toxicity in lungs induced by application of antitumor drug BLM in C57 tumour-bearing black mice. To achieve the ultimate goal of this research, we investigated the levels of lipid peroxidation (MDA) and activities of antioxidant defence enzyme superoxide dismutase (SOD) and catalase (CAT) in homogenates isolated from lungs, hearts and kidneys of tumour-bearing mice treated by the anti-tumor drugs DOX and BLM alone and compared to the levels of the same parameters measured after pretreatment with SLENU.

\section{Materials and Methods}

\subsection{Drugs and Chemicals}

Doxorubicin and Bleomycin were obtained from Bristol Myers Squibb, Wallingford, CT, USA). Buttermilk xanthine oxidase, SULF (sulfanilamide), NEDD (N-(1-naphthyl) ethylenediamine dihydrochloride) and $\mathrm{VCl}_{3}$ were obtained from Fluka (Germany). SLENU was synthesized according to Gadjeva and Koldamova, (2001). The test compounds were dissolved ex tempore: first step in Tween and second step in saline. 


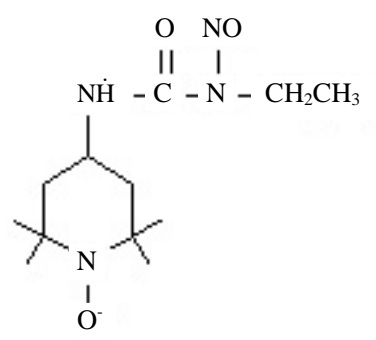

Figure 1. Chemical structure of the spin-labelled nitrosourea 1-ethyl-3-[4-(2,2,6, 6-tetramethylpiperidine-1oxyl)]-1-nitrosourea (SLENU), used in this study.

\subsection{Experimental Animals}

All procedures performed on animals were done in accordance with guidelines of the Bulgarian government regulations and were approved by the authorities of Trakia University. The animals were housed in plastic cages, fed a normal laboratory diet and water ad libitum. The study was carried out on 142 C57 tumor-bearing mice black (bred in the Laboratory of Oncopharmacology, National Cancer Institute, Sofia), average weight, 18 - 22 g, divided into groups of 6 animals per group (equal number of the two sexes) were used.

\subsection{Experimental Design}

The blood for the analysis was taken by a heart puncture after opening the thoracic region. The venous blood samples were divided into portions. The serums were used for an analysis of enzymatic activities and the level of NO. Mice were sacrificed by cervical decapitation at 1 hour after administration of the drugs lungs, hearts and kidneys were removed and kept on ice until homogenization on the same day. The samples were first washed with deionized water to separate blood and then homogenized. The tissue homogenates were centrifuged at $15000 \mathrm{rpm}$ for 10 minutes at $4^{\circ} \mathrm{C}$ and the final supernatants were obtained. They were used for determination of lipid peroxidation, and the activities of superoxide dismutase and catalase.

On day 0 , mice were inoculated i.p. with $10^{5}$ tumor cell suspension from lymphoid leukemia L1210 in saline in volume of $0.5 \mathrm{ml}$. On day 3, Bleomycin (60 mg/kg), Doxorubicine (60 mg/kg), in accordance with LD50 of the drugs, spin labeled nitrosourea SLENU $(100 \mathrm{mg} / \mathrm{kg})$ and combinations of them were administrated i.p. in a single injection in volume $0.1 \mathrm{ml}$ per body weight, as $10 \%$ Tween solutions in accordance with the routine methods described in the literature [19] [20].

\subsection{Investigation of Oxidative Stress Parameters}

\subsubsection{Analysis of Lipid Peroxidation}

Basal levels of lipid peroxidation as indicated by thiobarbituric acid-reactive substances (TBARS) were determined using the thiobarbituiric acid (TBA) method, which measures the malondialdehyde (MDA) reactive products according to Draper and Hadley, (1990) [21]. In the TBARS assay $1 \mathrm{ml}$ of the supernatant, $1 \mathrm{ml}$ of normal saline and $1 \mathrm{ml}$ of $25 \%$ trichloroacetic acid (TCA) were mixed and centrifuged at $2000 \mathrm{rpm}$ for $2 \mathrm{mi}$ nutes. One $\mathrm{ml}$ of protein free supernatant was taken, mixed with $0.25 \mathrm{ml}$ of $1 \% \mathrm{TBA}$ and boiled $1 \mathrm{~h}$ at $95^{\circ} \mathrm{C}$. After cooling the absorbance of the pink color of the obtained fraction product was read at $532 \mathrm{~nm}$.

\subsubsection{Measurement of Antioxidant Enzymes Activities}

Total SOD activity was determined by the xanthine/xanthine-oxidase/nitroblue tetrazolium (NBT) method according to Sun et al., (1988) [22] with minor modification. Superoxide anion radical $\left(\cdot \mathrm{O}_{2}^{-}\right)$produced by xanthine/xanthine-oxidase system reduced NBT to formazan, which can be assessed spectrophotometrically at 560 $\mathrm{nm}$. SOD competes with NBT for the dismutation of $\cdot \mathrm{O}_{2}^{-}$and inhibits its reduction. The level of this reduction is used as a measure of SOD activity. The total SOD activity is expressed in units/mg of protein, where one unit was equal to SOD activity that cause 50\% inhibition of the reaction rate without SOD. The assay of CAT activity was according to Beers and Sizer, (1952) [23]. Briefly, hydrogen peroxide (30 mM) was used as a substrate and the decrease in $\mathrm{H}_{2} \mathrm{O}_{2}$ concentration at $22^{\circ} \mathrm{C}$ in a phosphate buffer ( $50 \mathrm{mM}, \mathrm{pH} 7.0$ ) was followed spectros- 
copically at $240 \mathrm{~nm}$ for $1 \mathrm{~min}$. The activity of the enzyme was expressed in units per mg of protein and 1 unit was equal to the amount of an enzyme that degrades $1 \mathrm{mM} \mathrm{H}_{2} \mathrm{O}_{2}$ per minute.

\subsubsection{Measurement of $\cdot N O$ in Serum}

Serum nitric oxide was measured in terms of its products, nitrite and nitrate, by the method of Griess, modified by Miranda et al. [24]. This method is based on a two-step process. The first step is the conversion of nitrate to nitrite using vanadium (III) and the second is the addition of sulphanilamide and $\mathrm{N}$ (-naphthyl) ethylenediamine (Griess reagent). This converts nitrite into a deep-purple azo compound, which was measured colorimetrically at $540 \mathrm{~nm}$. Nitric oxide products were expressed as $\mu \mathrm{M}$.

\subsubsection{Statistical Analysis}

The data are expressed as a mean \pm SE. The data were analyzed by one-way ANOVA and Student's t-test was used to determine the statistical differences between groups. Statistical significance was considered at $\mathrm{p}<0.05$.

\section{Results}

\subsection{Effect of SLENU on MDA Level}

The levels of lipid peroxidation in homogenates isolated from lungs, hearts and kidneys of tumour-bearing mice treated with BLM and DOX alone and in combination with SLENU are shown in Figure 2. No significant differences, were observed when compared MDA levels in lung, heart and kidney homogenates of the treated with SLENU mice to those of the control mice (mean $0.449 \mu \mathrm{M}$ vs. $0.508 \mu \mathrm{M}, \mathrm{p}>0.05 ; 0.590 \mu \mathrm{M}$ vs. $0.485 \mu \mathrm{M}, \mathrm{p}>$ 0.05 and $0.656 \mu \mathrm{M}$ vs. $0.595 \mu \mathrm{M}, \mathrm{p}>0.05$ ). 1 hour after administration of DOX and BLM, the levels of MDA were significantly increased in all homogenates isolated from lungs, hearts and kidneys in tumor-bearing mice,

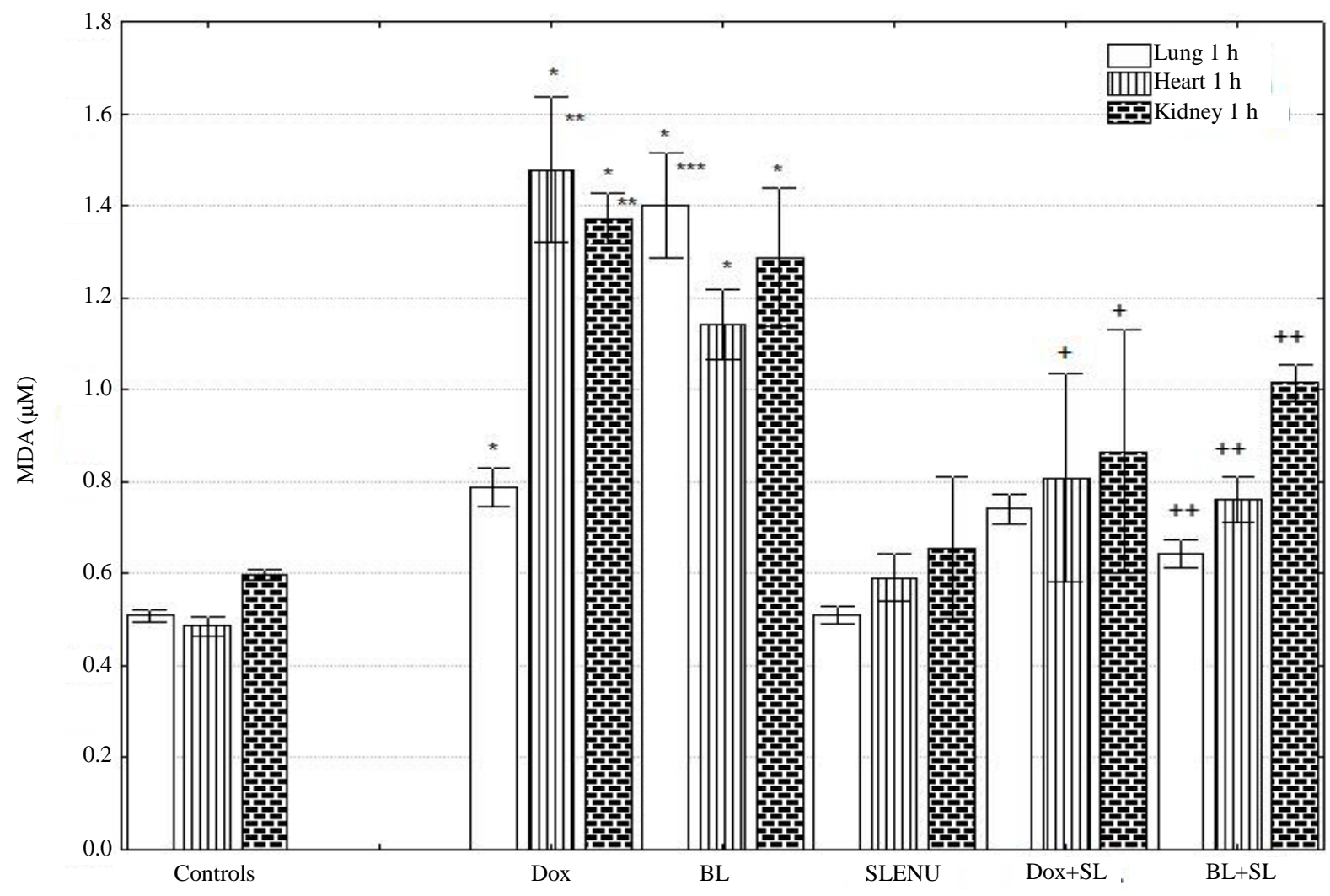

Figure 2. MDA in homogenates, isolated from mice treated with DOX, BLM, SLENU, and their combinations. Values are expressed as mean \pm SE. ${ }^{*} \mathrm{p}<0.0001$ vs. tumour-bearing controls; ${ }^{* *} \mathrm{p}<0.0001$ vs. lungs treated with DOX; $* * * p<0.01$ vs. hearts treated with BLM; $+p<0.001$ vs. corresponding groups treated with DOX alone; $++p<0.0001$ vs. corresponding groups treated with BLM alone. 
compared to the control groups ( $\mathrm{p}<0.0001)$. It should be noted that homogenates isolated from hearts of tumour-bearing mice treated with DOX had about 50\% higher level of MDA compared to homogenates isolated from lungs of the same mice (mean $1.478 \mu \mathrm{M}$ vs. $0.787 \mu \mathrm{M}, \mathrm{p}<0.0001$ ) and homogenates isolated from lungs in tumour-bearing mice treated with BLM had significantly higher level of MDA compared to homogenates isolated from mice hearts (mean $1.341 \mu \mathrm{M}$ vs. $1.140 \mu \mathrm{M}, \mathrm{p}<0.01$ ). The level of MDA in homogenates isolated from kidney of mice treated with DOX was higher but not significantly than those treated with BLM (mean $1.371 \mu \mathrm{M}$ vs. $1.289 \mu \mathrm{M}, \mathrm{p}>0.05$ ). However, combined application of DOX and SLENU led to significant decrease in the level of MDA in homogenates isolated from hearts and kidney compared to the corresponding levels when DOX was administrated alone (mean $0.807 \mu \mathrm{M}$ vs. $1.478 \mu \mathrm{M}$, and $0.927 \mu \mathrm{M}$ vs. $1.371 \mu \mathrm{M}, \mathrm{p}<0.001$ ). Combination of BLM with SLENU led also to a strong decrease in the levels of MDA in homogenates isolated from lungs compared to the MDA levels when BLM was administrated alone (mean $0.643 \mu \mathrm{M}$ vs. $1.341 \mu \mathrm{M}, \mathrm{p}$ $<0.0001$ ) and were also close to the MDA levels obtained from SLENU when administered alone.

\subsection{Effect of SLENU on Antioxidant Enzymes SOD and CAT}

As can be seen from the data represented in Figure 3 no significant differences were observed in SOD activities measured in lung, heart and kidney of tumor bearing mice treated with SLENU comparing to those of the controls (mean 5.49 U/gPr, vs. $6.55 \mathrm{U} / \mathrm{gPr}, \mathrm{p}>0.05 ; 6.423 \mathrm{U} / \mathrm{gPr}$ vs. $5.19 \mathrm{U} / \mathrm{gPr}, \mathrm{p}>0.05$ and $5.736 \mathrm{U} / \mathrm{gPr}$ vs. 5.29 $\mathrm{U} / \mathrm{gPr}, \mathrm{p}>0.05$ ). After treatment with DOX and BLM alone, SOD activities of all homogenates isolated from lungs, hearts and kidney in tumor-bearing mice were found to be significantly higher than those of the tumor bearing controls $(\mathrm{p}<0.001)$. However, for mice treated with DOX, SOD activities of homogenates isolated from hearts were significantly higher than those isolated from lungs (15.28 U/gPr vs. $12.35 \mathrm{U} / \mathrm{gPr}, \mathrm{p}<0.01)$. For mice treated with BLM, SOD activities of homogenates isolated from lungs were significantly higher than those determined in hearts (15.23 U/gPr vs. $11.45 \mathrm{U} / \mathrm{gPr}, \mathrm{p}<0.01)$. Pretreatment with SLENU and following application of DOX had significantly lower SOD activities of homogenates isolated from lungs and hearts compared to the

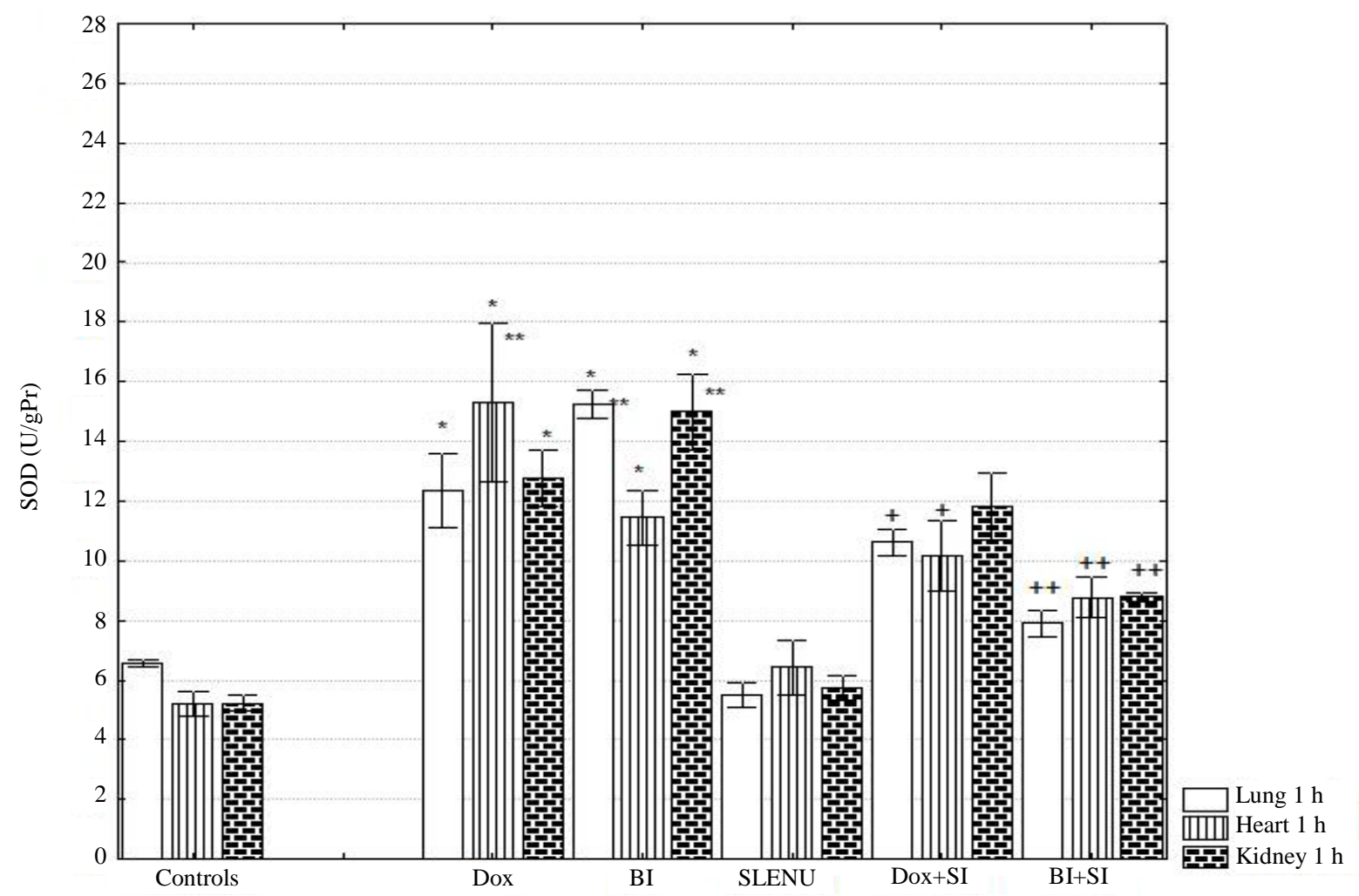

Figure 3. SOD activity of homogenates, isolated from mice treated with DOX, BLM, SLENU, and their combinations. Values are expressed as mean \pm SE. ${ }^{*} p<0.001$ vs. tumour-bearing controls; ${ }^{* *} \mathrm{p}<0.01$ vs. lungs; $+\mathrm{p}<0.001$ vs. corresponding DOX alone and $++\mathrm{p}<0.0001$ vs. corresponding groups with BLM alone. 
corresponding groups tumor bearing mice treated with DOX alone (mean $10.61 \mathrm{U} / \mathrm{gPr}$ and $10.14 \mathrm{U} / \mathrm{gPr}, \mathrm{p}<$ 0.001). A combined application of BLM and SLENU led to significant decrease in the level of SOD of homogenates isolated from lungs, hearts and kidneys, compared to the corresponding groups tumor bearing mice treated with BLM alone (mean 7.90 U/gPr; $8.75 \mathrm{U} / \mathrm{gPr}$ and $8.79 \mathrm{U} / \mathrm{gPr}, \mathrm{p}<0.0001$ ). Moreover, in lung homogenates for this combination were found SOD activities close to those of the controls.

Figure 4 represents the activity of the antioxidant enzyme CAT in homogenates isolated from lungs, hearts and kidneys of tumor bearing treated and untreated (control) mice. The activity of CAT in the homogenates isolated from lungs, hearts and kidneys after treatment with SLENU was not significantly higher compared to the controls (mean 29.232 U/gPr; $31.80 \mathrm{U} / g P r$ and $31.518 \mathrm{U} / g P r, p ~>0.05$ ). 1 hour after application of BLM or DOX the activities of CAT in all homogenates isolated from lungs, hearts and kidney in tumor bearing mice were decreased compared to the tumor bearing controls $(\mathrm{p}<0.001)$. However, it should be noted that homogenates isolated from hearts in tumor-bearing mice treated with DOX had significantly lower level of CAT compared to homogenates isolated from lungs (mean $17.74 \mathrm{U} / \mathrm{gPr}$ vs. $21.25 \mathrm{U} / \mathrm{gPr}, \mathrm{p}<0.01$ ) and homogenates isolated from lungs in tumor-bearing mice treated with BLM had significantly lower level of CAT compared to homogenates isolated from hearts (mean $20.43 \mathrm{U} / \mathrm{gPr}$ vs. $24.33 \mathrm{U} / \mathrm{gPr}, \mathrm{p}<0.001$ ). However, pretreatment with SLENU and following application of BLM or DOX led to significantly increase in the levels of the antioxidant enzyme CAT compared to the groups of tumor bearing mice with BLM and DOX administrated alone ( $<$ 0.001). Moreover, for both combinations were found that CAT activities in lung, heart and kidney homogenates were close to those of the controls $(\mathrm{p}>0.05)$.

\subsection{Effect of SLENU on Total End Products of $\mathrm{NO}_{2}^{-}$and $\mathrm{NO}_{3}^{-}$in the Serum}

Figure 5 shows the levels of $\cdot \mathrm{NO}$ expressed as total end products of $\mathrm{NO}_{2}^{-}$and $\mathrm{NO}_{3}^{-}$. The levels of $\cdot \mathrm{NO}$ were

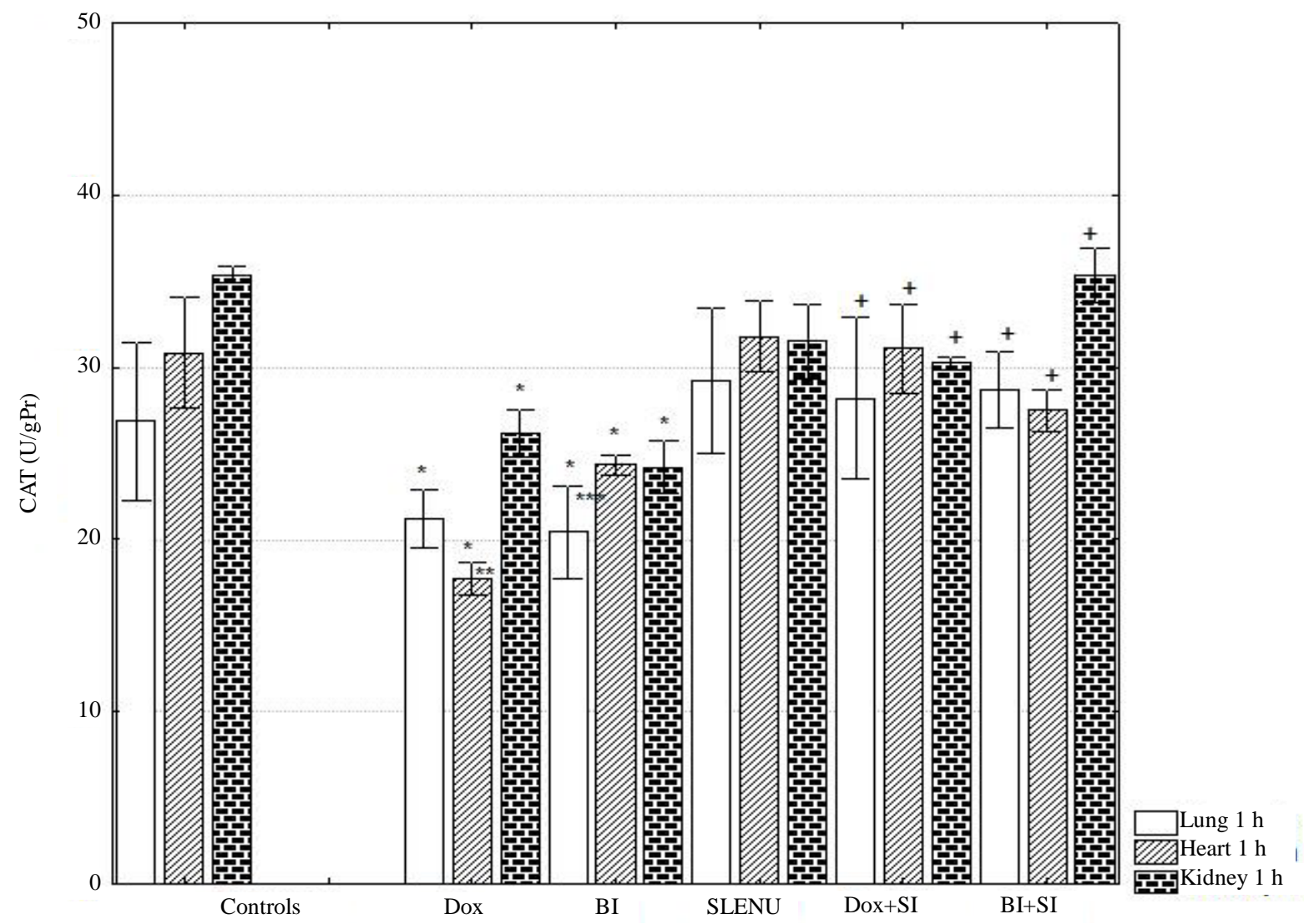

Figure 4. CAT activity of homogenates, isolated from mice treated with DOX, BLM, SLENU, and their combinations. Values are expressed as mean \pm SE. ${ }^{*} p<0.001$ vs. tumor-bearing controls; ${ }^{* *} p<0.01$ vs. lungs; ${ }^{* * *} p<0.001$ vs. hearts; $+p<$ 0.001 vs. corresponding groups with DOX or BLM alone. 


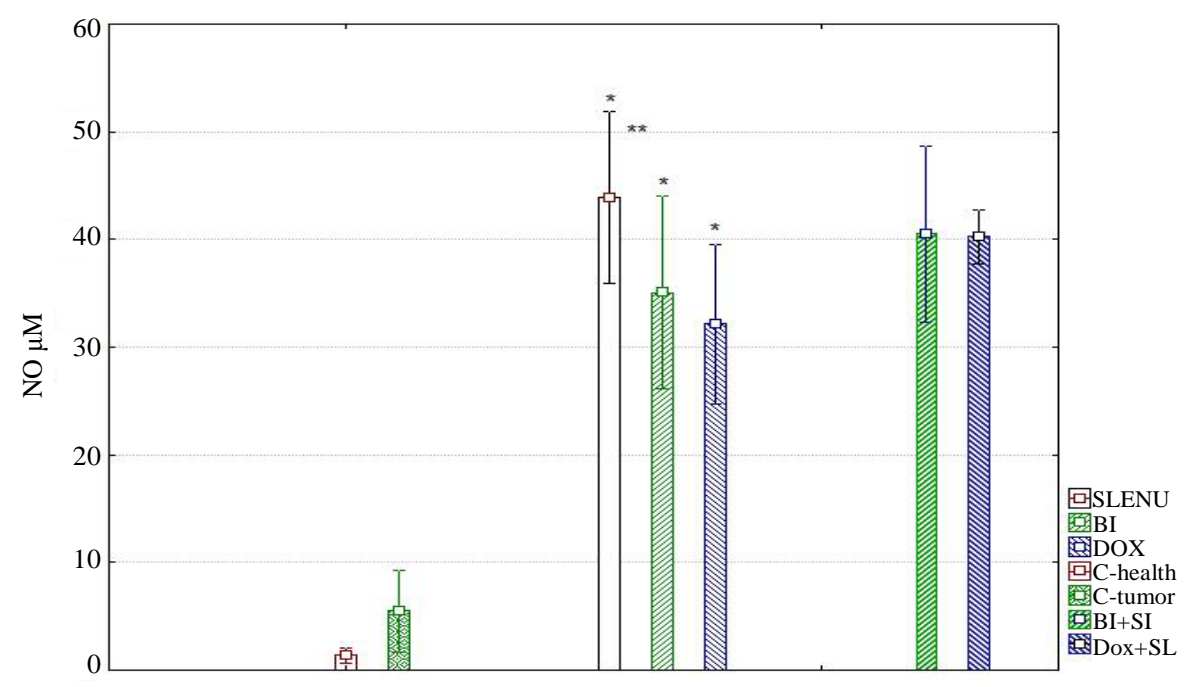

Figure 5. $\mathrm{NO}$ expressed as total end products of $\mathrm{NO}_{2}^{-}$and $\mathrm{NO}_{3}^{-} \cdot{ }^{*} \mathrm{p}<0.00001$ vs. controls; ${ }^{* *} \mathrm{p}<0.0001$ vs. groups with DOX or BLM alone.

found to be increased but not significantly in tumor bearing mice compared to healthy controls (mean $5.781 \mu \mathrm{M}$ vs. $1.373 \mu \mathrm{M}, \mathrm{p}>0.05$ ). Tumor bearing mice treated with BLM or DOX had remarkably increased levels of $\cdot \mathrm{NO}$ compared to the tumor controls (mean $35.252 \mu \mathrm{M}, 33.915 \mu \mathrm{M}, \mathrm{p}<0.00001$, resp.). It is interesting that mice treated with SLENU had also significantly higher level of $\cdot \mathrm{NO}$ than that of tumor controls (mean $44.088 \mu \mathrm{M}, \mathrm{p}$ $<0.00001)$ and also than mice treated with BLM and DOX alone, $(\mathrm{p}<0.0001)$. Moreover, the levels of $\cdot \mathrm{NO}$ for the combinations of BLM or DOX, with SLENU were not significantly different from those in mice treated with SLENU alone (mean $40.088 \mu \mathrm{M}, 40.187 \mu \mathrm{M}, \mathrm{p}>0.05$, resp.).

\section{Discussion}

Reactive oxygen species (ROS) were shown to be involved in the toxicity of both DOX and BLM. Free radicals have been shown to exhaust the antioxidant defence system and hence elevate the oxidation process of lipids in heart tissues of DOX-treated rats [25] [26]. Increased malondialdehyde equivalents, SOD activity and carbonyl contents in lung tissue produced by BLM were also reported by Teixeira et al. 2008 [8].

The present results showed that 1-hour following treatment with DOX heart and kidney homogenates of tumour-bearing mice had significantly higher productions of lipid peroxidation compared to lungs homogenates. It was accompanied by increased activity of the antioxidant defence enzyme SOD and decrease of CAT. This disturbance might be a sequel of the augmented predominantly generation of toxic reactive oxygen species in the heart and kidney. In the present study, BLM-induced oxidative stress was confirmed by significantly higher productions of prevailing lipid peroxidation in lungs compared to hearts and kidneys. It was also accompanied by elevation of the antioxidant activity of SOD and decrease in CAT enzymes. Augmented generation of toxic ROS, which were products of DOX and BLM metabolism, found support in previous studies [25]-[28].

Based on this finding we have hypothesized that if BLM and DOX could generate $\mathrm{O}_{2}^{-}$and $\mathrm{NO}$ in vivo, it might contribute to tissue $\mathrm{ONOO}^{-}$and ${ }^{\circ} \mathrm{OH}$ production and these could be a reason for the oxidative toxicity (increase in MDA level and alteration in SOD and CAT activities) by the following Reactions (I):

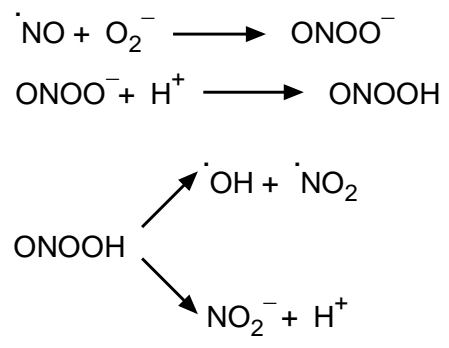


Mice were treated with the typical antioxidant studied-SLENU possessing high SSA [15]. Our results showed that SLENU did not increase the levels of MDA in tumor-bearing mice indicating that the compound did not induce oxidative stress. The same was true for the antioxidant profile (SOD and CAT) as treatment with SLENU alone did not show any effect. However, after the concomitant treatment with SLENU and DOX or SLENU and BLM complete suppression of the oxidative stress was observed. MDA levels were decreased, and antioxidant enzymes SOD and CAT activities were restored to levels close to the control. It should be mentioned that for SLENU no organ selectivity was found. Our results showing decreased MDA levels of mice treated by the combinations of SLENU with DOX or BLM supposed a reduced ROS production that might be explained by the effect of SLENU on DOX and BLM-induced oxidative injury through one and the same mechanism.

Using EPR spectroscopy methods, we showed that the antioxidant effect of SLENU was attributed to its high superoxide scavenging activity (SSA) and the mechanism of that activity was through redox cycling between nitroxide and its corresponding hydroxylamine moiety [15]:

$$
\begin{aligned}
& \mathrm{N}-\mathrm{O}_{+}^{+} \cdot \mathrm{O}_{2}^{-}+\mathrm{H}^{+} \stackrel{\mathrm{k}_{\mathrm{r}}}{\longrightarrow} \mathrm{N}-\mathrm{OH} \\
& \mathrm{N}-\mathrm{OH}+{ }^{\cdot} \mathrm{O}_{2}^{-}+\mathrm{H}^{+} \stackrel{\mathrm{k}_{0}}{\longrightarrow} \mathrm{N}-\mathrm{O}^{\cdot}+\mathrm{H}_{2} \mathrm{O}_{2}
\end{aligned}
$$

where, $k_{\mathrm{r}}$, and $\mathrm{k}_{\mathrm{o}}$ were second-order rate constants for the reduction of nitroxide and oxidation of hydroxylamine by superoxide, respectively.

The non-toxic effect of the spin-labelled nitrosourea SLENU and its ability to reverse the BLM and DOX -induced oxidative stress in our study have led us to propose the following hypothesis. The nitroso group in the spin-labeled nitrosourea SLENU may lead to the generation of 'NO when SLENU is used alone or jointly with BLM and DOX. However, the nitroxyl free radical moiety incorporated only in the spin-labeled compound might successfully compete with the self-generated ' $\mathrm{NO}$ produced by BLM and DOX in the scavenging of $\mathrm{O}_{2}^{-}$. This effect could prevent formation of highly toxic species such as $\mathrm{ONOO}^{-}$and ${ }^{\circ} \mathrm{OH}$ and at the same time could increase the level of 'NO. In this regard, our present results are consistent with the notion that the protective effects of SLENU are due to both SSA and its increased release of $\cdot \mathrm{NO}$.

In our study serum levels of nitrite $\left(\mathrm{NO}_{2}^{-}\right)$and nitrate $\left(\mathrm{NO}_{3}^{-}\right)$were used to estimate the level of ' $\mathrm{NO}$ formation, since $\mathrm{NO}$ was highly unstable and had a very short half-life. We observed significantly higher 'NO end products in the plasma of mice treated with BLM, DOX and SLENU alone and also in mice treated with the combination of drugs with SLENU. These results were in agreement with the results reported by other authors. Gurujeyalakshmi reported increase in NO levels as a result from BLM-induced increases in iNOS message and iNOS protein [29]. Several in vitro studies have demonstrated the protective effect of 'NO in oxidative injury. Rubbo et al. suggested that 'NO might act as a primaryantioxidant in biological systems by limiting lipid peroxidative chain propagation [30]. Using a model system, authors demonstrated that $\mathrm{NO}$ was a potent terminator

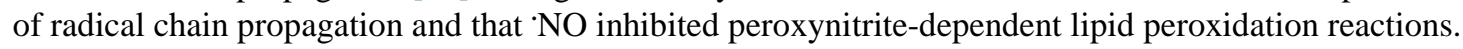

Such a chemopreventive effect of the nitroxide Tempol had been reported by several authors [31]-[33]. Mitchell et al., demonstrated that nitroxides at non-toxic concentrations were effective as in vitro and in vivo antioxidants when oxidation was induced by the superoxide, hydrogen peroxide, organic hydroperoxides, ionising radiation, or specific DNA-damaging anticancer agents [34].

In view of these facts, we can conclude that the non-toxic effect of the spin-labelled nitrosourea SLENU, and its ability to reverse the DOX- and BLM-induced oxidative stress in our study have led us to propose that pretreatment with SLENU can markedly suppress the oxidative toxic manifestations, observed in DOX- and BLMtreated mice by scavenging of $\mathrm{O}_{2}^{-}$and increased $\mathrm{NO}$ release. However, further studies are needed to clarify the effect of these combinations in anti-tumour chemotherapy applied to experimental animals.

\section{References}

[1] Singal, P.K. and Iliskovic, N. (1998) Doxorubicin Induced cardiomyopathy. The New England Journal of Medicine, 339, 900-905. http://dx.doi.org/10.1056/NEJM199809243391307

[2] Kalender, Y., Yel, M. and Kalender, S. (2005) Doxorubicin Hepatotoxicity and Hepatic Free Radical Metabolism in Rats. The Effects of Vitamin E and Catechin. Toxicology, 209, 39-45. http://dx.doi.org/10.1016/j.tox.2004.12.003

[3] Yagmurca, M., Bas, O., Mollaoglu, H., Sahin, O., Nacar, A. and Karaman, O. (2007) Protectiveeffects of Erdosteine on 
Doxorubicin-Induced Hepatotoxicity in Rats. Archives of Medical Research, 38, 380-385. http://dx.doi.org/10.1016/j.arcmed.2007.01.007

[4] Luna, M.A., Bedrossian, C.W., Lichtiger, B. and Salem, P.A. (1972) Interstitial Pneumonitis Associated with Bleomycin Therapy. American Journal of Clinical Pathology, 58, 501-510.

[5] Szapiel, S.V., Elson, N.A., Fulmer, J.D., Hunninghake, G.W. and Crystal, R.G. (1979) Bleomycin-Induced Interstitial Pulmonary Disease in the Nude, Athymic Mouse. The American Review of Respiratory Disease, 120, 893-899.

[6] Gutteridge, J.M. and Xiao Change, F. (1981) Protection of Iron Catalysedthe Radical Damage to DNA and Lipids by Copper (II) Bleomycin. Biochemical and Biophysical Research Communications, 99, 1354-1360. http://dx.doi.org/10.1016/0006-291X(81)90768-3

[7] Filderman, A.E., Genovese, L.A. and Lazo, J.S. (1988) Alterations in Pulmonaryprotective Enzymes Following Systemic Bleomycin Treatment in Mice. Biochemical Pharmacology, 37, 1111-1116. http://dx.doi.org/10.1016/0006-2952(88)90518-7

[8] Teixeira, K.C., Soares, F.S., Rocha, L.G., Silveira, P.C., Silva, L.A., Valença, S.S., Dal Pizzol, D.F., Streck, E.L. and Pinho, R.A. (2008) Attenuation of Bleomycin-Induced Lung Injury and Oxidative Stress by N-Acetylcysteine Plus Deferoxamine. Pulmonary Pharmacology \& Therapeutics, 21, 309-316. http://dx.doi.org/10.1016/j.pupt.2007.07.006

[9] Raikov, Z., Todorov, D. and Ilarionova, M. (1985) Synthesis and Study of Spin-Labeled Nitrosoureas. Cancer Biochemistry Biophysics, 4, 343-348,

[10] Gnewuch, C.T. and Sosnovsky, G. (1997) A Critical Appraisal of the Evolution of N-Nitrosoureas as Anticancer Drugs. Chemical Reviews, 97, 829-1013. http://dx.doi.org/10.1021/cr941192h

[11] Zheleva, A., Raikov, Z., Ilarionova, M., Carpenter, B., Todorov, D. and Armstrong, N. (1996) Potential Antimelanomic Drugs: I. Synthesis and Antimelanomic Effect of a Spin Labelled D, L-Amino Acid Containing a 2-Chloroethylnitrosocarbamoyl Group. Pharmazie, 51, 602-604.

[12] Gadjeva, V. and Raikov, Z. (1999) Syntheses and Antitumor Activity of 4-\{N'-[N-(2-Chloroethyl)-N-Nitrosocarbamoyl]Hydrazono\}-2,2,6,6-Tetramethylpiperidine-1-Oxyl. Die Pharmazie, 54, 231-232.

[13] Gadjeva, V. and Koldamova, R. (2001) Spin-Labeled 1-Alkyl-1-Nitrosourea Synergists of Antitumor Antibiotics. Anticancer Drug Design, 16, 247-253.

[14] Gadjeva, V., Zheleva, A., Lazarova, G. (2003) Spin Labeled Antioxidants Protect Bacteria against the Toxicity of Alkylating Antitumor Drug CCNU. Toxicology Letters, 144, 289-294.

[15] Gadzheva, V., Ichimory, K., Nakazawa, H. and Raikov, Z. (1994) Superoxide Scavenging Activity of Spin-Labeled Nitrosourea and Triazene Derivatives. Free Radical Research, 21, 177-186. http://dx.doi.org/10.3109/10715769409056568

[16] Gadjeva, V.D., Kuchukova, D., Tolekova, A. and Tanchev, S. (2005) Beneficial Effects of Spin-Labelled Nitrosourea on CCNU-Induced Oxidative Stress in Rat Blood Compared with Vitamin E. Die Pharmazie, 60, 530-532.

[17] Gadjeva, V., Tolekova, A. and Vasileva, M. (2007) Effect of the Spinlabelled 1-Ethyl-1-Nitrosourea on CCNUInduced Oxidative Liver Injury. Pharmazie, 62, 608-613.

[18] Gadjeva, V., Grigorov, B., Nikolova, G., Tolekova, A., Zheleva, A. and Vasileva, M. (2013) Protective Effect of SpinLabeled 1-Ethyl-1-Nitrosourea against Oxidative Stress in Liver Induced by Antitumor Drugs and Radiation. BioMed Research International, 2013, Article ID: 924870.

[19] Geran, R.S., Greenberg, N.H., Macdonald, M.M., Schumacher, A.M. and Abbott, B.J. (1972) Protocols for Screening Chemical Agents and Natural Products against Animal Tumors and Other Biological Systems. Cancer Chemotherapy Reports, 13, 1-87.

[20] White, B.A., Erickson, M.M. and Stevens, S.C. (1970) Chemistry for Medical Technologists. Mosby, Saint Louis.

[21] Draper, H.H. and Hadley, M. (1990) Malondialdehyde Determination as an Index of Lipid Peroxidation. Methods in Enzymology, 186, 421-431. http://dx.doi.org/10.1016/0076-6879(90)86135-I

[22] Sun, Y., Oberley, L.W. and Li, Y. (1988) A Simple Method for Clinical Assay of Superoxide Dismutase. Clinical Chemistry, 34, 497-500.

[23] Beers, R. and Sizer, T. (1952) Spectrophotometric Method for Measuring the Breakdown of Hydrogenperoxide by Catalase. Journal of Biological Chemistry, 195, 133-138.

[24] Miranda, K.M., Espey, M.G. and Wink, D.A. (2001) A Rapid, Simples Pectrophotometric Method for Simultaneous Detection of Nitrate and Nitrite. Nitric Oxide, 5, 62-71. http://dx.doi.org/10.1006/niox.2000.0319

[25] Dalloz, F., Maingon, P., Cottin, Y., Briot, F., Horiot, J.C. and Rochette, L. (1999) Effect of Combined Irradiation and Doxorubicin Treatmenton Cardiac Function and Antioxidant Defenses in the Rat. Free Radical Biology and Medicine, 26, 785-800. http://dx.doi.org/10.1016/S0891-5849(98)00259-7 
[26] Yilmaz, S., Atessahin, A., Sahna, E., Karahan, I. and Ozer, S. (2006) Protective Effect of Lycopene on Adriamycin-Induced Cardiotoxicity and Nephrotoxicity. Toxicology, 218, 164-171. http://dx.doi.org/10.1016/j.tox.2005.10.015

[27] Kappus, H. (1987) Oxidative Stress in Chemical Toxicity. Archives of Toxicology, 60,144-149. http://dx.doi.org/10.1007/BF00296968

[28] Serrano-Mollar, A., Closa, D., Prats, N., Blesa, S., Martinez-Losa, M., Cortijo, J., Estrela, J.M., Morcillo, E.J. and Bulbena, O. (2003) In Vivo Antioxidant Treatment Protects against Bleomycin-Induced Lung Damage in Rats. British Journal of Pharmacology, 138, 1037-1048. http://dx.doi.org/10.1038/sj.bjp.0705138

[29] Gurujeyalakshmi, G., Wang, Y. and Giri, S.N. (2000) Suppression of Bleomycin-Induced Nitric Oxide Production in Mice by Taurine and Niacin. Nitric Oxide, 4, 399-411. http://dx.doi.org/10.1006/niox.2000.0297

[30] Rubbo, H., Radi, R. and Trujillo, M. (1994) Nitric Oxide Regulation of Superoxide and Peroxynitrite-Dependent Lipid Peroxidation. Formation of Novel Nitrogen-Containing Oxidized Lipid derivatives. Journal of Biological Chemistry, 269, 26066-26075.

[31] Samuni, A.M., DeGraff, W., Krishna, M.C. and Mitchell, J.B. (2002) Nitroxides as Antioxidants: Tempol Protects against $\mathrm{EO}_{9}$ Cytotoxicity. Molecular and Cellular Biochemistry, 234-235, 327-333. http://dx.doi.org/10.1023/A:1015974126615

[32] Thiemermann, C., McDonald, M.C. and Cuzzocrea, S. (2001) The Stable Nitroxide, Tempol, Attenuates the Effects of Peroxynitrite and Oxygen-Derived Free Radicals. Critical Care Medicine, 29, 223-224. http://dx.doi.org/10.1097/00003246-200101000-00055

[33] Thiemermann, C. (2003) Membrane-Permeable Radical Scavengers (Tempol) for Shock, Ischemia-Reperfusion Injury, and Inflammation. Critical Care Medicine, 31, S76-S84. http://dx.doi.org/10.1097/00003246-200301001-00011

[34] Mitchell, J.B., Krishna, M.C., Kuppusamy, P., Cook, J.A. and Russo, A. (2001) Protection against Oxidative Stress by Nitroxides. Experimental Biology andMedicine, 226, 620-621. 
Scientific Research Publishing (SCIRP) is one of the largest Open Access journal publishers. It is currently publishing more than 200 open access, online, peer-reviewed journals covering a wide range of academic disciplines. SCIRP serves the worldwide academic communities and contributes to the progress and application of science with its publication.

Other selected journals from SCIRP are listed as below. Submit your manuscript to us via either submit@scirp.org or Online Submission Portal.
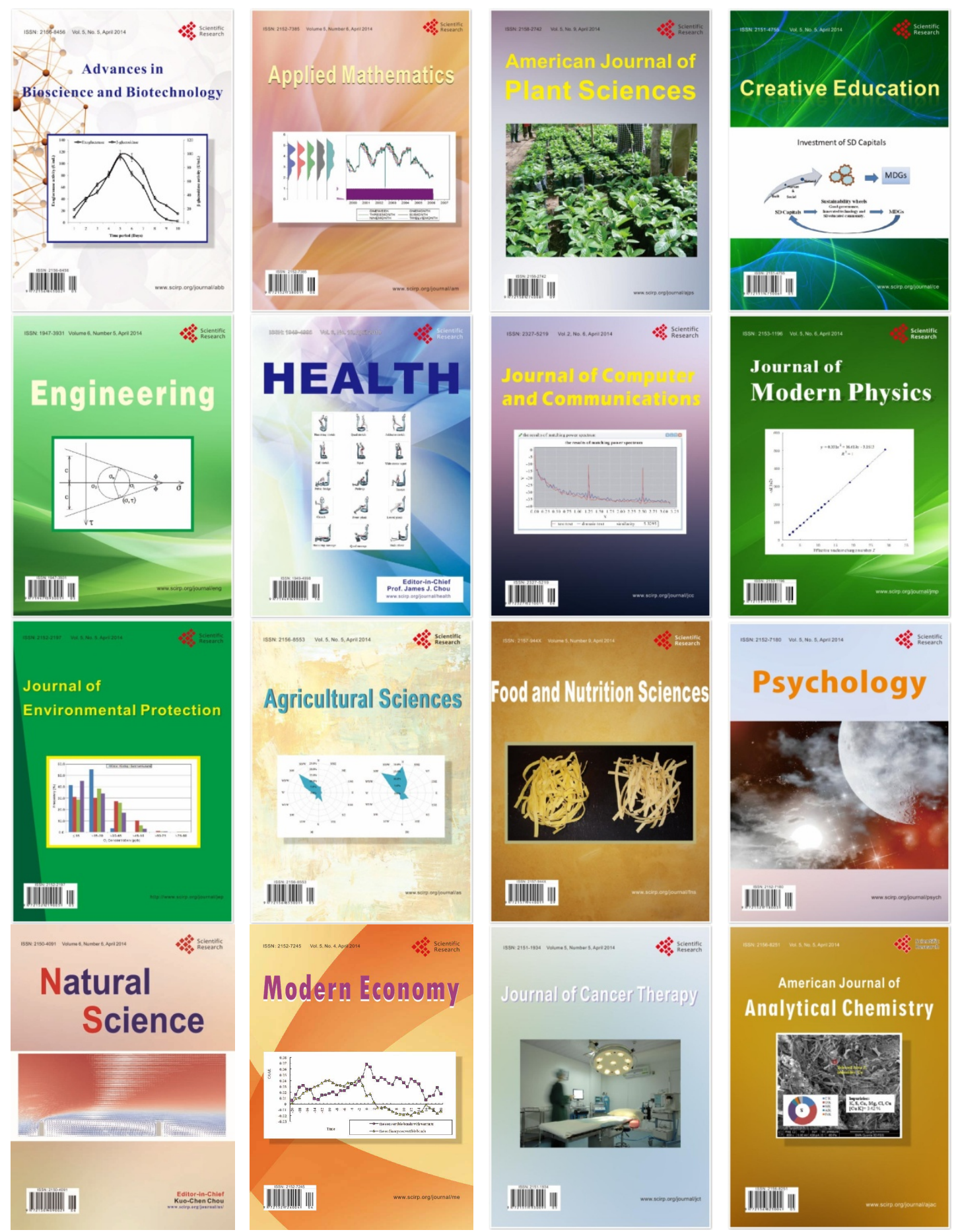